\title{
Estimation of The Radioactive Source Term from RDE Accident Postulation
}

\author{
Pande Made Udiyani, Ihda Husnayani, M. Budi Setiawan, Sri Kuntjoro, Hery Adrial, Amir Hamzah \\ Center for Nuclear Reactor Technology and Safety (PTKRN) - BATAN Puspiptek Complex, No. 80, Tangerang Selatan, 15310, Indonesia
}

\section{ARTICLE INFO}

Article history:

Received: 10 September 2019

Received in revised form: 29 Oktober 2019

Accepted: 30 Oktober 2019

Keywords:

RDE

HTGR

Radioactive

Source term

accident

\begin{abstract}
A B S T R A C T
The design process of Experimental Power Reactor (Reaktor Daya Eksperimental/RDE) has been carried out by BATAN for the last five years, adopting HTGR-type reactor with thermal power of $10 \mathrm{MW}$. RDE is designed with the reference of similar reactor, namely HTR- 10 . During this process, source term estimation is required to prove the safety of RDE design, as well as to fulfill the concept of As Low As Reasonably Achievable (ALARA) in radiation protection. The source term is affected by the magnitude of the radioactive substances released from the reactor core due to an accident. Conservative accident postulations on the RDE are water ingress and depressurization accidents. Based on these postulations, source term estimation was performed. It follows the mechanistic source term flow, with conservative assumptions for the radioactive release of fuel into the coolant, reactor building, and finally discharged into the environment. Assumptions for the calculation are taken from conservative removable parameters. The result of source term calculation due to the water ingress accident for Xe-133 noble gas is $8.97 \mathrm{E}+12 \mathrm{~Bq}, \mathrm{Cs}-137$ is $3.59 \mathrm{E}+07 \mathrm{~Bq}$, and $\mathrm{I}-131$ is $4.34 \mathrm{E}+10 \mathrm{~Bq}$. As for depressurization accident, the source term activity for $\mathrm{Xe}-133$ is $3.90 \mathrm{E}+13 \mathrm{~Bq}$, Cs- 137 is $1.56 \mathrm{E}+07 \mathrm{~Bq}$, and I131 is $1.89 \mathrm{E}+10 \mathrm{~Bq}$. The source term calculation results obtained in this work shows a higher number compared to the HTR-10 source term used as a reference. The difference is possibly due to the differences in reactor inventory calculations and the more conservative assumptions for source term calculation.
\end{abstract}

\section{INTRODUCTION}

The priority of BATAN activities in the energy sector for the past five years is the design development of Experimental Power Reactor (ReaktorDayaEksperimental/RDE). RDE is a high temperature gas-cooled reactor (HTGR) with a power of $10 \mathrm{MWt}$, which is expected to be capable to conduct experiments related to high temperatures and partial fulfillment of electrical energy for the Serpong Nuclear Region in Puspiptek [1-5]. HTGR

Pande Made Udiyani. Tel./Fax.: +62-8128958248

E-mail: pmade-u@batan.go.id

DOI: $10.17146 / \mathrm{tdm} \cdot 2019.21 .3 .5583$ isa GenIV advanced reactor concept. The reactor uses pebble fuel which contain thousands of microsized TRISO-coated fuel particles embedded within a graphite matrix. The coating consists of four layers that serve to hold the fission products inside the fuel element. The coolant used is helium and its moderatoris graphite [2,4-11]. Thanks to these features, unlike the light water reactor (LWR), HTGR is meltdown-proof $[2,11]$. TRISO coatings are divided into layers consisting of a buffer, an inner pyro-carbon (IPyC), a silicon carbide ( $\mathrm{SiC})$, and an outer pyrocarbon (OPyC) layer. It functions as a barrier to fission products in the kernel from being released to other systems such as reactor 
core, coolant, and reactor building. The principle of defence in depth in HTGR is realized as five barriers, namely fuel particle kernel, silicon carbide and pyrocarbon coatings of the fuel particle, fuel matrix and fuel element graphite, primary circuit, and reactor building, successively [11-13].

Source term is defined as a radioactive material that can and potentially escapes into the environment from a particular system. The composition and size of the source term depend on the type of reactor, type of fuel, reactor power, size of reactor inventory, safety system, and its postulation of normal operation or accidental. In addition to its composition and activity, source term refers to physical and chemical form, itshalf life, and thermal energy [2,7]. The source term calculation on RDE is needed to prove the safety of the design and the radiation impacts from the operation of the RDE.

Source term calculations for normal operations of RDE [2,4], HTR-10 [10], and other HTGR have been carried out by other researchers [11-12]. Source term calculations for accidents particularly for water ingress and depressurization have also been carried out $[10,13]$. Accident source term calculations were performed using simulation, experimental, and modeling methods.

In this study, the mechanistic source term approach was used. Mechanistic approach is a calculation using a model of radioactive material release from the fuel element, the cooling system, the reactor building and finally to the environment. The release fraction of each subsystem uses parameters that have been generated by other researchers either through experiments or simulations. This method is used due to the limited software we currently own.

Until recently, the source term during accident condition was taken from similar reactor, HTR-10 $[10,13]$. Since we have obtained RDE core inventory calculation, RDE source term of accident would be calculated based on the RDE inventory. The source term calculation for RDE postulated accident uses parameters for the source term mechanistic model. This method is used to obtain comprehensive accident source term data which is calculated based on the RDE design. The calculation results will be compared with the HTR10 source term, and the pessimistic calculation results will be used for radiological dose calculations in the RDE site environment.

\section{THEORY}

HTGR core consists of thousands of pebble arranged stochastically in a cylindrical or annular space. The properties of TRISO particles are one of the most important factors in determining the radiological safety of HTGR. TRISO fuel particles consist of micro-sized fuel kernels, usually in form of uranium dioxide $\left(\mathrm{UO}_{2}\right)$ or uranium oxycarbide (UCO). TRISO coatings, which suopposed to retain fission products in fuels, are designed as such so that it can tolerate HTGR core temperature [11-17].

A TRISO coating consists of four layers, namely buffer, inner pyrocarbonlayer (IPyC), silicon carbide $(\mathrm{SiC})$, and outer pyrocarbon layer (OPyC) [11-18]. Each layer has a task to prevent fission products from leaking out of TRISO. Fuel kernels contain fissile and fertile materials, they provide as a confinement for fission products. In addition, each layer also serves as prevention to coating damage from gas infiltration that can react and erode fuel. The porous carbon layer serves to support and accommodate if swelling were to occur on the kernel. The IPyC functions to prevent CI from entering the kernel during fabrication, and reduce tensile stress at $\mathrm{SiC}$ layer. Meanwhile, $\mathrm{SiC}$ functions as part of the main bearing and prevents gaseous and metallic fission products from diffusing out.The IPyC coating which is tightly bound to the $\mathrm{SiC}$ layer also helps maintain the $\mathrm{SiC}$ layer during compression and irradiation, and has a stable dimension. The $\mathrm{SiC}$ coating is the most important coating in TRISO layers, since it provides most of structural strength and dimensional stability as well as serves as a major barrier to the release of fission products, particularly volatile metals like cesium. High density IPyC coatings which shrink when irradiated also produce compressive stresses in the stable $\mathrm{SiC}$ dimension, partly compensated for the tensilestress component caused by internal gas pressure. IPyC coatings are also effective at maintaining fission gases in fabricated fuel particles or $\mathrm{SiCs}$ that fail to function up to about $1800^{\circ} \mathrm{C}$ [11-15].

Radioactive material that is released and becomes source term is modeled with the following assumptions: (1) the release of fission product (FP) into the primary system due to defective fuel resulted by fabrication limitations, (2) the corrosion of graphite coatings due to oxidation reactions with corrosive compounds such as water and gas, reducing its confinement of fission products, and (3) the release of FP diffuses through layers in accordance to temperature increase [19-21]. A small part of the initial failure of coated fuel particles is the conservatively assumed range between the $1.0 \mathrm{E}-4$ and $1.0 \mathrm{E}-3$, based on the experience of fabricating HTGR fuels $[11,15]$. The types of HTGR accidents that can significantly produce source term are core heating and oxidation reactions, leakage due to defective materials, and 
depressurization of the primary circuit. Core heating events for medium-sized HTGR can result in the release of a portion of the inventory attached to the fuel dement. Whereas for small-sized HTGR, the release of accidental influx of water and depressurization events concentrate on the contamination that accumulates in the main circuit during long-term operation.

Source term estimation starts from the calculation of core inventory. The calculation is performed using ORIGEN2.1, a versatile fuel depletion and radioactive decay computer code. ORIGEN is often used to simulate fuel cycles and calculating several important characteristics of nuclear material, such as nuclide composition, radioactivity, toxicity, neutron emission, and photon emission. Calculation method used in ORIGEN2.1 is based on an ordinary differential equation which is represented the buildup and decay process of radionuclides as follows[14]:

$$
\begin{aligned}
\frac{d X_{i}}{d t}=\sum_{j=1}^{N} l_{i j} \lambda_{j} X_{j} & +\varphi \sum_{k=1}^{N} f_{i k} \sigma_{k} X_{k} \\
& -\left(\lambda_{i}+\varphi \sigma_{i}+r_{i}\right) X_{i} \\
& +F_{i}, \quad i=1, \ldots ., N
\end{aligned}
$$

where $X_{i}$ is the density of nuclide $i, N$ is the number of nuclide, $l_{i j}$ is fraction of radioactive disintegration by other nuclide, which lead to formation of species $i$, $j$ is the number of iteration starting from $j=1$ through $j=N, \varphi$ is position- and energy-averaged neutron flux, $f_{i k}$ is fraction of neutron absorption by other nuclides, which lead to formation of species $i, \sigma_{\mathrm{k}}$ is spectrumaveraged neutron absorption cross section of nuclide $k, r_{i}$ is continuous removal rate of nuclide $i$ from the system, and $F_{i}$ is continuous feed rate of nuclide $i$.

\section{METHODOLOGY}

The source term calculation uses the mechanistic source term model following the model in Figure 1. It starts with in the reactor inventory calculation using calculated data based on full core postulation. The assumption made in this research is that the reactor core in equilibrium condition. The core consists of fuel layers where each layer contains fuel with an increasing burnup from the top to the bottom. The top layer in filled with fresh fuel and the bottom layer is filled with fuel with burnup level of 70,000 MWD/THM. In total, 135 $\mathrm{kg}$ of fuel is irradiated with a power of $10 \mathrm{MWt}$ to reach a maximum burnup of 80,000 MWD/MTH [1].

Based on Figure 1, it is assumed conservatively that fission product release from fuel particles is $8.00 \mathrm{E}-04$ and for fuel particle incremental release is $5.00 \mathrm{E}-04$. The primary coolant activity is the sum of fission products release from fuel particles and fuel particle incremental releases. The efficiency in the purification system of noble gas (NG) is $0 \%$, for I and $\mathrm{H}-3$ are $90 \%$, and for other nuclides are $99 \%$. Release fraction to the reactor building for water ingress accidents is $23 \%$ for all types of fission products. Release fraction for depressurization accident is $100 \%$ for NG, $\mathrm{H}-3$, and C-14; while I and other nuclides are $10 \%$. Efficiency of reactor building of the HVAC System for I is $90 \%$ and for other nuclides are 99\% [4,10-12, 20-22].

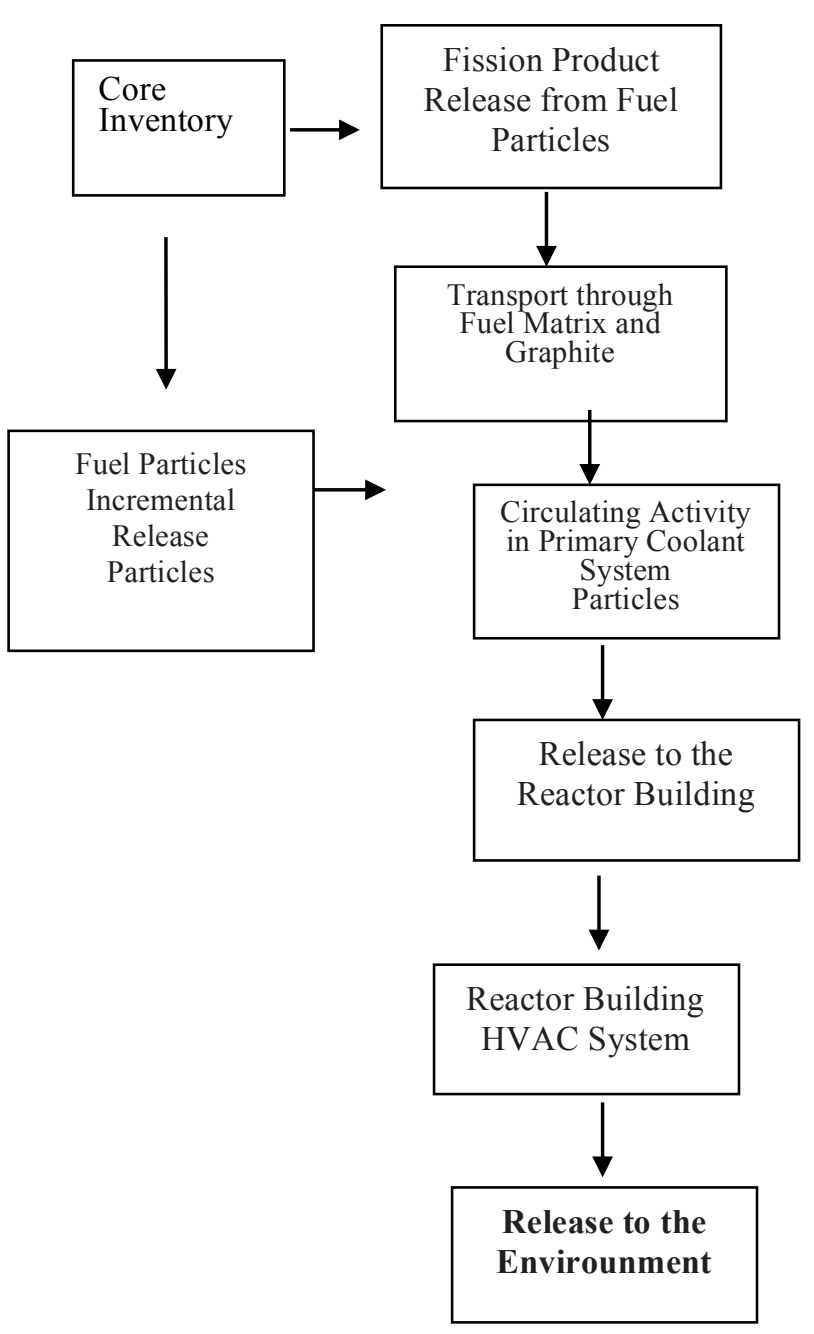

Figure 1. RDE Mechanistic source term model for estimation of accident postulation 


\section{RESULTS AND DISCUSSION}

\section{Water ingress accidents}

Water ingress will cause corrosion in TRISO from the oxidation reaction of graphite with water. Due to corrosion in TRISO, the fission product is released into the reactor core. Other causes are due to the process of desorption and washing. Based on the conservative assumption as described in the methodology, the calculation results are shown in Figure 2 for noble gases, and Figure 3 for other fission products.

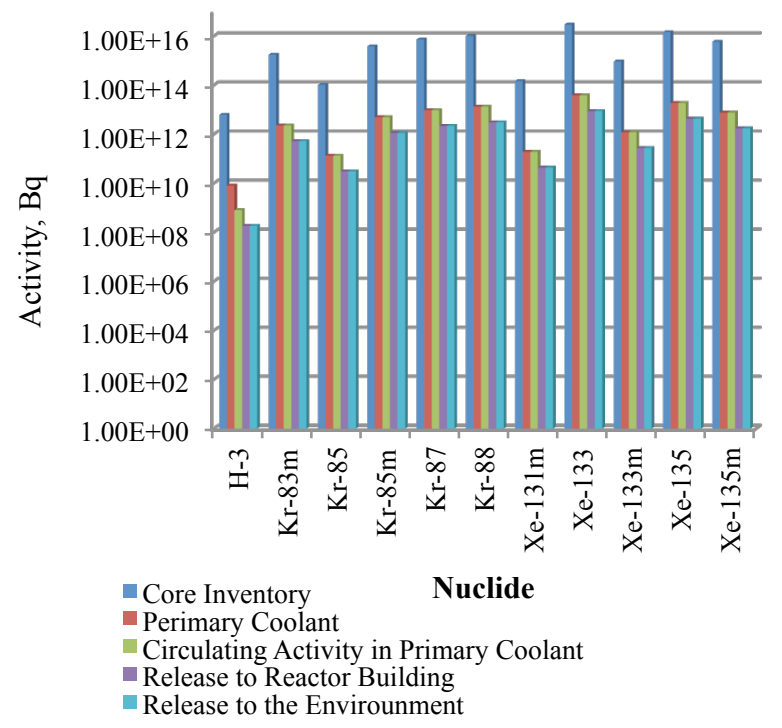

Figure 2: Noble gas source term for Water Ingress Accident

The helium purification system will reduce the activity of some fission products. High efficiency in the purification system will significantly filter fission products, especially from metals such as cesium, strontium, and other metallic fission products. The helium purification system filter is able to capture $99 \%$ of metal fission products in the primary cooling system, and $90 \%$ of I and H-3 gases. Meanwhile, noble gases are assumed to completely pass the helium primarysystem, since they do not interact with matter. Retained fission products will be deposited on the surface of the cooling system.

The assumption of fission products released from the helium primary system to the reactor building is $23 \%$ for all types of fission products. Fission products released from the reactor building into the environment are postulated through the reactor building filter. In that case, the stack filter efficiency is $99 \%$ for I and $90 \%$ for other nuclides, whereas the noble gas is assumed to be $100 \%$ released from the reactor building. Figure 2 and
Figure 3 showed that the results of source term calculation for the water ingress accident are 8.97E $+12 \mathrm{~Bq}$ for $\mathrm{Xe}-133$ noble gas, $3.59 \mathrm{E}+07 \mathrm{~Bq}$ for $\mathrm{Cs}-137$, and $4.34 \mathrm{E}+10 \mathrm{~Bq}$ for $\mathrm{I}-131$ fission products.

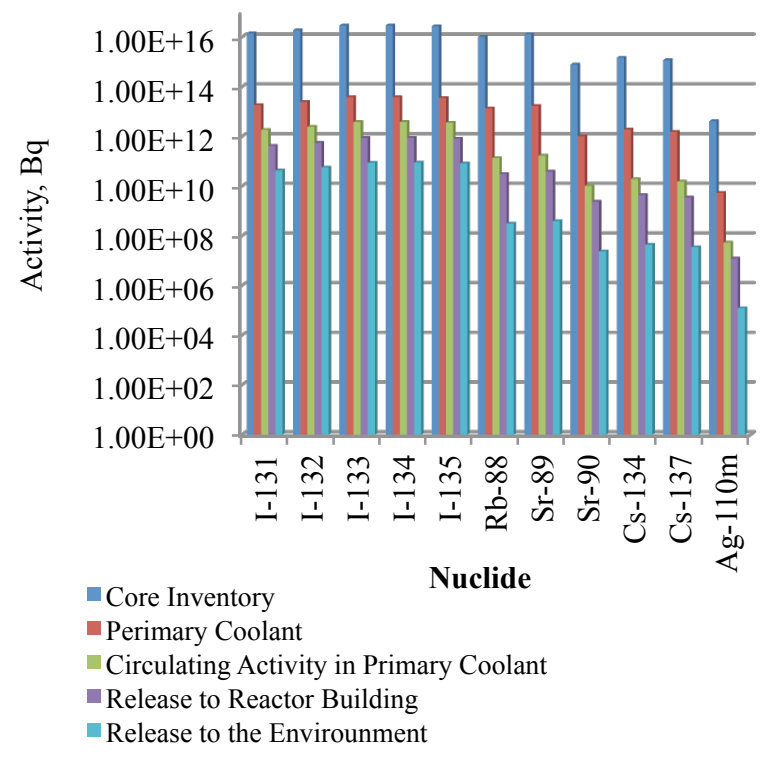

Figure 3: Fission product source term for Water Ingress Accident,

\section{Depressurization accidents}

Depressurization accidents result in loss of pressure on the primary coolant. This results in fission products diffusion in TRISO due to the increase of temperature, desorption, and the failure of particles. The fission product is released into the helium coolant caused by the desorption process due to pressure drop and corrosion after decomposition of the concrete. Accumulation of fission products which deposited on the surface of the helium primary cooling system will be released to the building due to reactor pressure depressurization. It is assumed that the fission product released from the cooling system to the reactor building is $100 \%$ for noble gas, $\mathrm{H}-3$, and C14, while $\mathrm{I}$ and other nuclides are $10 \%$. The efficiency of Reactor Building HVAC System are $90 \%$ for I and $99 \%$ for other nuclides. The results of source term estimation due to the depressurization accident are shown in Figure 4 for the noble gas and in Figure 5 for other fission products. 


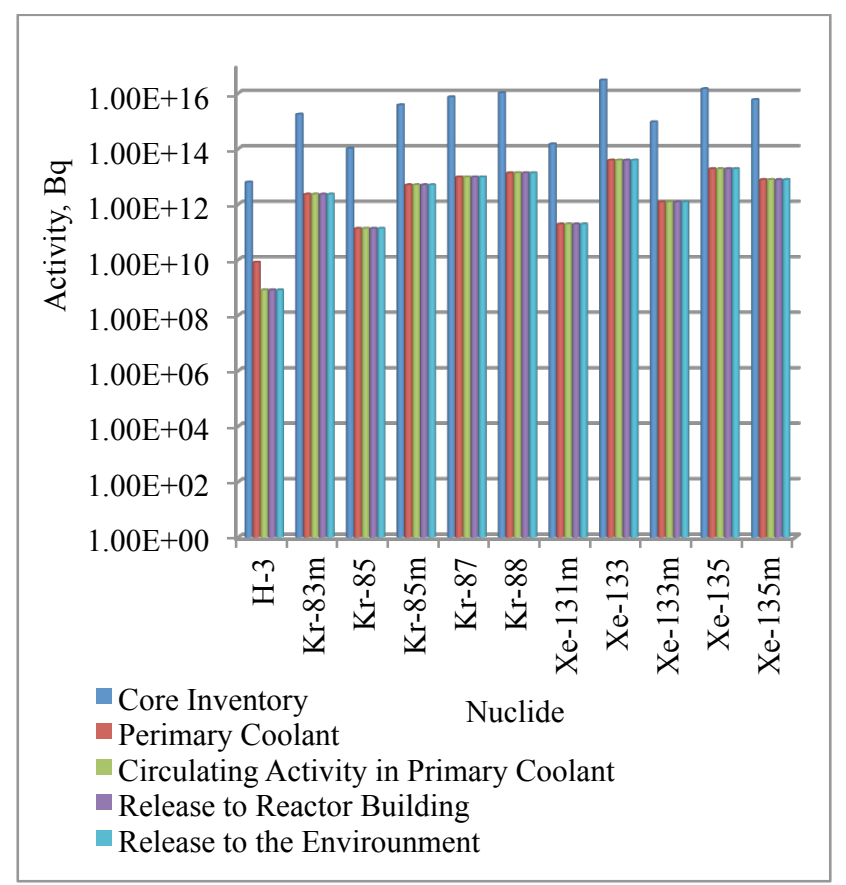

Figure 4: Noble gas source term for depressurization accident

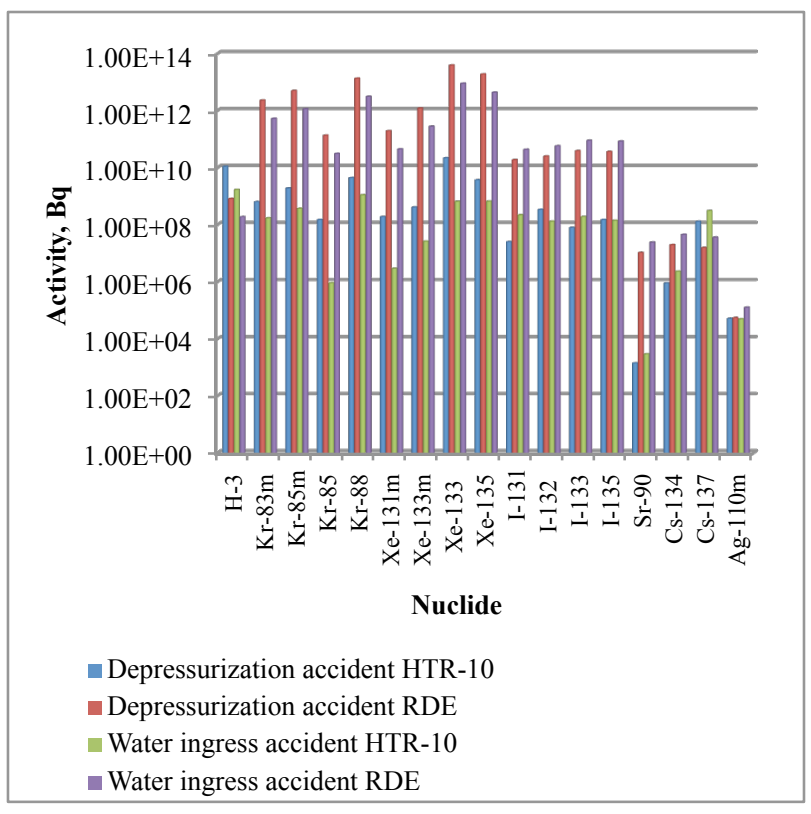

Figure 5. Comparison of water ingress and depressurization accident source term between RDE and HTR-10

The results of source term calculation for the depressurization accident at Figure 3 for noble gases and Figure 4 for other fission products are $3.90 \mathrm{E}+13 \mathrm{~Bq}$ for $\mathrm{Xe}-133,1.56 \mathrm{E}+07 \mathrm{~Bq}$ for Cs-137, and1.89E+10 Bq for I-131. Those values for RDE are higher compared to the HTR-10 source term used as a reference (Figure 5). This difference is possible because of differences in reactor inventory calculations and more conservative assumptions for source term calculation.

Figure 5 also shows the differences in source term due to the water ingress and depressurization accidents for RDE and HTR-10. Noble gas activities for depressurization accident is higher than water ingress, due to differences in the release assumptions from the cooling system to the reactor building. The former assumed that $100 \%$ noble gas release from the coolant to the reactor building for accident depressurization, while the latter is $23 \%$ for all nuclides. Nonetheless, the activity of other fission products is higher in water ingress accidents since the assumed release of fission products other than noble gases in depressurization accident is $10 \%$.

Figure 5 also shows that the noble gas activities at RDE source term is higher compared to the reference reactor of HTR-10. This is due to differences in the assumptions taken in this study that noble gas cannot interact with any material, so that the filter in the primary cooling purification system and in the reactor building stack cannot prevent the release of noble gas into the environment. It is expected that the source term is calculated from postulations and very conservative assumptions illustrates the reliability and safety of $\mathrm{RDE}$ designs. Based on the RDE source term, the radiological impact of the RDE accident can be calculated, which is used in thepreparation of the Emergency Planning Zone (EPZ) in the RDE site environment.

\section{CONCLUSION}

Source term calculations for water ingress and depressurization accident for $\mathrm{RDE}$ design have been done using a mechanistic source term model. The estimation was performed using conservative removable parameter assumptions.The result of source term calculation for the water ingress accident are $8.97 \mathrm{E}+12 \mathrm{~Bq}$ for $\mathrm{Xe}-133$ noble gas, $3.59 \mathrm{E}+07 \mathrm{~Bq}$ for $\mathrm{Cs}-137$, and $4.34 \mathrm{E}+10 \mathrm{~Bq}$ for I131. For the depressurissation accident, the source term activities are $3.90 \mathrm{E}+\mathrm{E}+13 \mathrm{~Bq}$ for $\mathrm{Xe}-133$, $1.56 \mathrm{E}+07 \mathrm{~Bq}$ for $\mathrm{Cs}-137$, and $1.89 \mathrm{E}+10 \mathrm{~Bq}$ for $\mathrm{I}-$ 131. In general,the source term calculation from this study showed a higher value compared to the HTR-10 source term used as a reference. The radiological impact of the $\mathrm{RDE}$ accident can be calculated based on this source term values, in order to prepare the EPZ in the RDE site environment. 


\section{ACKNOWLEDGMENT}

The works were conducted under the government reseach and funding, which was managed by Center for Nuclear Reactor Technology and Safety (PTKRN), BATAN, for the year of 2017. It was also partially supported by 2018-2019 National Research Incentive of RISTEK-DIKTI ministry.

\section{REFERENCES}

1. Kuntjoro S., Udiyani P.M. Analisis Inventori Reaktor Daya Eksperimental Jenis Reaktor Gas Temperatur Tinggi. Urania. 2016. 22(1):53-64.

2. Udiyani P.M., Kuntjoro S., Sunaryo G.R, Susiati H. Atmospheric Dispersion Analysis for Expected Radiation Dose due to Normal Operation of RSG-GAS and RDE Reactors. Atom Indonesia. 2018.44 (3) :115-121

3. Husnayani I., and Udiyani P.M. Radionuclide Characteristic of RDE Spent Fuels. Tri Dasa Mega. 2018. 20 (2):69-76.

4. Udiyani P.M. and Kuntjoro S. Estimation of Routine Discharge of Radionuclides on Power Reactor Experimental RDE. Urania. 2017. 23 (1):45-51.

5. Udiyani PM., Kuntjoro S., Setiawan M.B., Husnayani I. Estimation of Radioactivity Impact for RDE based on HTR-10 hypthetical accident - a case study. in: International Symposium of Emerging Nuclear Technology and Engineering Novelty. IOP Conf. Series: Journal of Physics: Conf. Series 1198 (2019) 022037

6. Zhang Z., Wu z., Wang D. Current Status and Technical Description of Chinese $2 \times 250$ MWth HTR-PM Demonstration Plant. Nucl. Eng. Des. 2009.239:1212-1219.

7. Thomas S.The Pebble Bed Modular Reactor: An obituary. Energy Policy. 2011. 39:24312440.

8. Verfondern K.,Cao J., Liu T., Conclusion from V\&V Studies on the German Codes PANAMA and FRESCO for HTGR Fuel Performance and Fision Product release. Nucl.Eng. Des. 2014. 271:84-91.

9. Shohei Ueta S., Aihara J., Sawa K., Yasuda A., Honda M., Furihata N. Development of High Temperature Gas-cooled Reactor (HTGR) fuel in Japan. Prog. Nucl. Energy. 2011. 53:788-793.

10. Yuanzhong L., Jianzhu C. Fission Product Release and its Environment Impact for
Normal Reactor Operations and for Relevant Accidents. Nucl. Eng. Des. 2002.218: 81-90

11. INL/EXT-10-17997. Mechanistic Source Terms White Paper, Idaho National Laboratory, July 2010

12. Ohashi H., Sato H., Tachibana Y., Kunitomi K., Ogawa M. Feasibily Study on Naturally Safe HTGR (NSHTR) for Air Ingress Accident. Nucl. Eng. Des. 2014.271:537-544.

13. Chen H.,Li C., Xing, H., Fang C. The R\&D of HTR-STAC Program Package: Source Term Analysis Codes for Pebble-Bed HighTemperature Gas-Cooled Reactor.Sci. Technol. Nucl.Ins. 2018. Article ID 7389121, 9 pages

14. Jeong H., Jeong Y.H., Chang S.H.. Comparison of Two Irradiation Testing Results of HTR-10 Fuel Spheres. Nucl. Eng. Des. 2009.239: 1066-1075..

15. Van Roojen I.J., Duzzik M.L., Van Roojen P.M.Silver (Ag) Transport in TRISO Coated Particel : A Critical review. Nucl. Eng. Des.. 2014.271:180-188.

16. Bombonia E., Cerulloa, N., Lomonaco G.Simplified Models for Pebble-bed HTR Core Burn-up Calculations with Monteburns2.0. Ann. Nucl. Energy.2012. 40: $72-83$.

17. Powersa J.J., Wirthb B.D. A Review of TRISO Fuel Performance Models. J. Nucl. Mater.2010. 405: 74-82.

18. Xhonneux A., Allelein H.J. Development of Integrated Fission Product Release and Transport Code for Spatially Resolved fullCore Calculations of V/HTRs. Nucl. Eng. Des. 2014.271:361-369.

19. Verfonderna K. , Xhonneuxa A., Nabielekb H., Alleleina H.J. Computational Analysis of Modern HTGR Fuel Performance and Fssion Product Release during the HFR-EU1 Irradiation Experiment. Nucl. Eng. Des. 2014. 271:385-7120.

20. Takamatsu K., Yan X.L., Nakagawa S., Sakaba N., Kunitomi, K. Spontaneous Stabilization of HTGRs without Reactor Scram and Core Cooling. Nucl. Eng. Des. 2014.271:379-387

21. Sato H.,Ohashi H., Tachibana Y., Kunitomi K., Ogawa M. Feasibily Study on Naturally Safe HTGR (NSHTR) for Air Ingress Accident. Nucl. Eng. Des. 2014.271:530-536

22. Herranz L.E., Fontanet J. Analysis of the Effect of Water ponds on HTR Confinement Behavior under Accident Conditions. Prog. Nucl. Energy.2013. 67:7-14 